\title{
Immunohistochemistry as a tool to identify ELP1-associated medulloblastoma
}

\author{
Arnault Tauziède-Espariat ${ }^{1,2,3} \cdot$ Léa Guerrini-Rousseau $^{4,5} \cdot$ Alexandre Perrier $^{6} \cdot$ Jacob Torrejon $^{7,8} \cdot$ Flavia Bernardi $^{7,8}$. \\ Pascale Varlet ${ }^{1,2,3}$ - Lauren Hasty ${ }^{1}$. Olivier Delattre ${ }^{3,8} \cdot$ Kévin Beccaria $^{9}$ - Alice Métais ${ }^{1}$ - Olivier Ayrault ${ }^{7,8}$. \\ Fabrice Chrétien $^{1,3} \cdot$ Franck Bourdeaut $^{10}$. Christelle Dufour ${ }^{4,5}$. Julien Masliah-Planchon ${ }^{6}$
}

Received: 19 December 2021 / Revised: 14 February 2022 / Accepted: 14 February 2022 / Published online: 23 February 2022

(c) The Author(s) 2022

The occurrence of a mutation in a cancer predisposition gene has been estimated to account for more than $40 \%$ of the medulloblastoma (MB), SHH-activated [3, 4]. Fourteen percent of them have been reported with bi-allelic alterations of ELP1, a tumor-suppressor gene being currently the most frequent to predispose to MB [4]. The ELPI gene encodes for the protein ELP1 which is a component of the elongator complex, a six-subunit protein complex (ELP1-6) implicated in neurogenesis [1, 2]. The bi-allelic inactivation of ELP1 results from the combination of a germline alteration and a loss of chromosome $9 q$ [4]. The aim of our study was to evaluate the sensitivity and specificity of ELP1 immunostaining to detect ELPI-associated MB.

Our study included a total of 132 DNA-methylation profiled MB: $57 \mathrm{SHH}$-activated (aged from 0- to 18-yearold), 15 WNT-activated, 30 group 3 , and 30 group 4 . We performed immunohistochemistry (IHC) for the ELP1 antibody (clone 6G9; 1:50 dilution; Sigma-Aldrich; Bromma, Sweden) on $3 \mu \mathrm{m}$-thick sections of formalin-fixed, paraffinembedded tissue samples, performed on an Omnis automate.

Franck Bourdeaut, Christelle Dufour and Julien Masliah-Planchon contributed equally to this work.

Arnault Tauziède-Espariat

a.tauziede-espariat@ghu-paris.fr

1 Department of Neuropathology, GHU Paris-Psychiatry and Neuroscience, Sainte-Anne Hospital, 1, rue Cabanis, 75014 Paris, France

2 Institut de Psychiatrie Et Neurosciences de Paris (IPNP), UMR S1266, INSERM, IMA-BRAIN, Paris, France

3 Université de Paris, Paris, France

4 Department of Children and Adolescents Oncology, Gustave Roussy, Paris Saclay University, Villejuif, France

5 Team "Genomics and Oncogenesis of Pediatric Brain Tumors", INSERM U981, Gustave Roussy, Paris Saclay University, Villejuif, France
Tumoral molecular analysis of ELPl was conducted with a custom Next-Generation Sequencing (NGS) panel (Supplementary table S1). The library was prepared with the SureSelect XT-HS according to the manufacturer's protocol (Agilent) and sequenced on an Illumina NovaSeq 6000. The sequence of all coding exons of ELP1 (NM_003640.4) and PTCH1 (NM_000264.3) and the loss of the heterozygosity (LOH) status of chromosome $9 q$ were analyzed afterward. Proteomic has been quantified by a data-independent acquisition method following the same protocol as in [4]. We selected a proteome dataset composed of $16 \mathrm{MB}, \mathrm{SHH}-$ activated with five samples showing the ELPI pathogenic variation identified by genome and proteome techniques and previously reported in [4]. Finally, we tested by immunohistochemistry other pediatric tumor types of the posterior fossa (47 ependymomas, group A, 15 ependymomas, group B, 10 embryonal tumors with multilayered rosettes, 10 atypical teratoid and rhabdoid tumors, 10 central nervous system tumors with BCOR internal tandem duplication, and 10 pilocytic astrocytomas).

A complete loss of cytoplasmic ELP1 staining in all tumor cells (with intra-tumoral vessels as a positive

6 Laboratory of Somatic Genetics, Curie Institute Hospital, Paris, France

7 Institut Curie, PSL Research University, CNRS UMR, INSERM, 91898 Orsay, France

8 Université Paris Sud, Université Paris-Saclay, CNRS UMR 3347, INSERM U1021, 91898 Orsay, France

9 Department of Pediatric Neurosurgery, Necker Hospital, APHP, Université Paris Descartes, Sorbonne Paris Cite, 75015 Paris, France

10 SIREDO Center Care, Innovation, Research in Pediatric, Adolescent and Young Adult Oncology, Curie Institute and Paris Descartes University, Paris, France 
internal control) was observed in 12/57 (21\%) of MB, SHH-activated (Fig. 1a-c), and was preserved in all other MB subgroups (Fig. 1d) and in other tumor types (Supplementary Fig. 1). Molecular analyses revealed the presence of bi-allelic ELPl alterations (Table 1 for details) in 11/12 MB, SHH-activated, where ELP1 stained negatively. Thus, the sensitivity and the specificity of the IHC were evaluated as $99 \%(121 / 122)$ and $100 \%$ (11/11), respectively, in MB. Interestingly, for the unique discordant case, proteomic analyses revealed concordant downregulated levels of ELP1 (Supplementary Fig. 2). From a molecular perspective, this MB harbored a chromosome 9q copyneutral LOH (confirmed by FISH analysis of chromosome
9) but the sequencing analysis failed to reveal any additional nucleotidic or copy number alteration at the ELPI locus.

Altogether, ELP1 IHC constitutes a fast, low-cost and conservative tissue-consuming method to detect ELPI-associated MB. Only one case presented a loss of expression without a bi-allelic alteration of ELP1 identified, suggesting the presence of a cryptic alteration (no deep intronic pathogenic variant, complex structural variant, promoter genomic alteration or hyper-methylation was detected with our NGS analysis). The higher proportion (19 vs. $14 \%$ in the literature) is explained by the large number of children in our cohort [4]. Here, none of the group $4 \mathrm{MB}(n=30)$ harbored
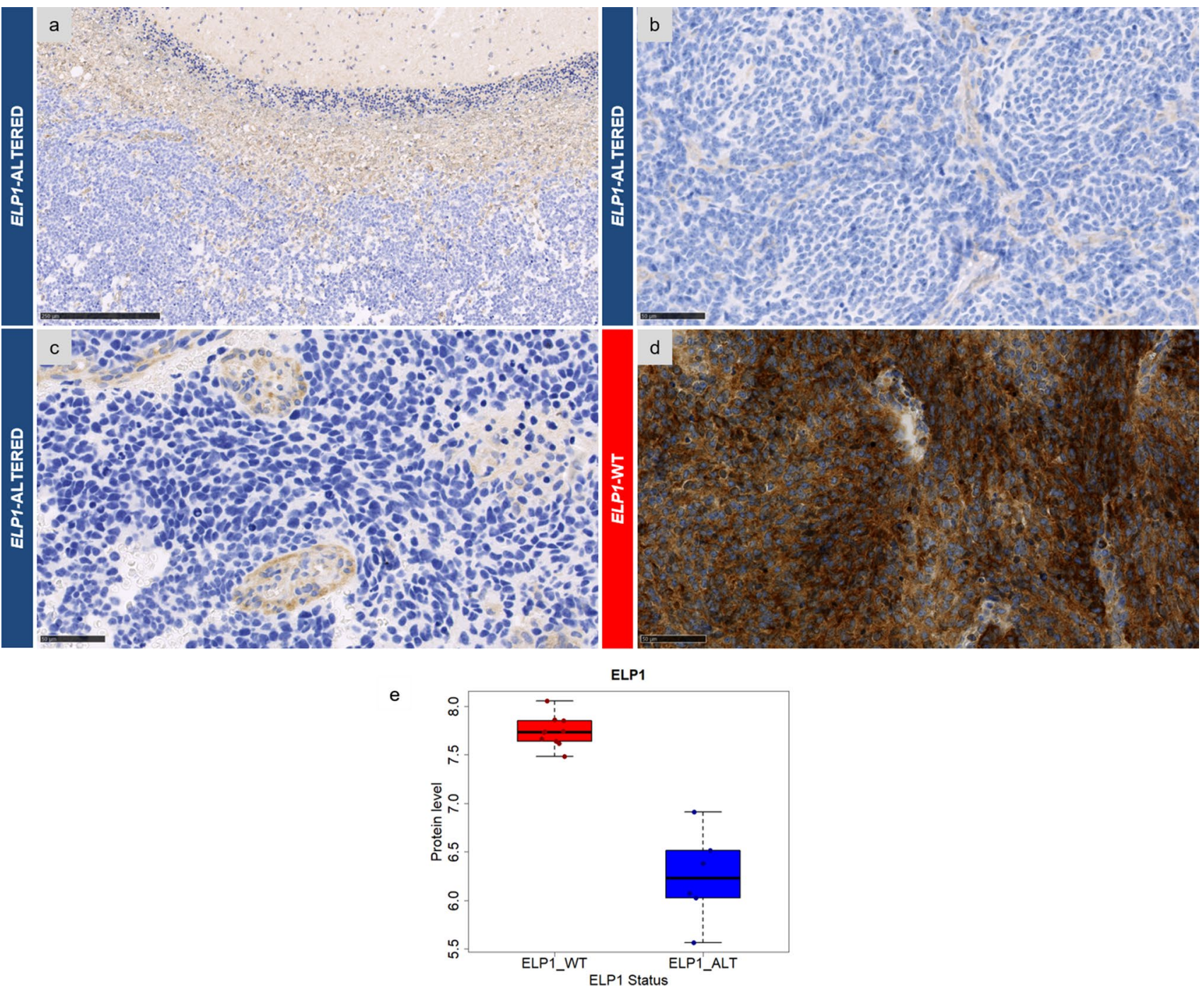

Fig. 1 ELP1 expression in medulloblastomas SHH-activated. Case 1: A distinct ELP1 loss in one case of medulloblastoma, SHH-activated, with a bi-allelic alteration of ELP1 with cerebellum parenchyma and vessels as positive internal controls (a, magnification, $\times 150)$. Case 1: A distinct ELP1 loss in one case of medulloblastoma, SHH-activated, with a bi-allelic alteration of ELP1 (b, magnification, $\times 400$, with endothelial cells as positive internal control). Case 7: A distinct ELP1 loss in one case of medulloblastoma, $\mathrm{SHH}$-activated, with a bi-allelic alteration of ELP1 (c, magnification, $\times 400$ ). A preserved expression of ELP1 in one case of medulloblastoma, SHH-activated, without alteration of ELP1 (d, magnification, $\times 400)$. Black scale bars represent $100 \mu \mathrm{m}(\mathbf{a})$ and $50 \mu \mathrm{m}(\mathbf{b}-\mathbf{d})$ 
Table 1 Histomolecular data of our cases with ELP1 loss of immuno-expression

\begin{tabular}{|c|c|c|c|c|c|c|c|}
\hline Case number & $\begin{array}{l}\text { Age at diag- } \\
\text { nosis (YO) }\end{array}$ & Histopathology & $\begin{array}{l}\text { Molecular } \\
\text { subgroup }\end{array}$ & IHC ELP1 & $\begin{array}{l}\text { SOMATIC ELP1 } \\
\text { ALTERATION }\end{array}$ & PTCH1 status & $9 \mathrm{q}$ status \\
\hline 1 & 2 & EN & $\begin{array}{l}\text { SHH-activated, } \\
\text { TP53-WT }\end{array}$ & Lost & $\begin{array}{r}\text { c. } 1622 \mathrm{~A}>\mathrm{G} / \mathrm{p} . \\
\text { (Glu541Gly) }\end{array}$ & $\begin{array}{l}\text { c.3131_3132insTGTCTT } \\
\text { CCTGCTGAACCCCTG } \\
\text { GACGGCCGGGATCAT } \\
\text { /p.A1044delinsAVFLLNPWTAGII }\end{array}$ & Loss \\
\hline 2 & 5 & $\mathrm{D} / \mathrm{N}$ & $\begin{array}{l}\text { SHH-activated, } \\
\text { TP53-WT }\end{array}$ & Lost & c. $2731 \mathrm{C}>\mathrm{T} / \mathrm{p} .\left(\mathrm{G} \ln 911^{*}\right)$ & c.3030dup/p.(Asn1011GlnfsTer134) & Loss \\
\hline 3 & 5 & $\mathrm{D} / \mathrm{N}$ & $\begin{array}{l}\text { SHH-activated, } \\
\text { TP53-WT }\end{array}$ & Lost & $\begin{array}{l}\text { c. } 1461-2 \mathrm{~A}>\mathrm{G} / \mathrm{p} . \\
\quad \text { (His681Leu) }\end{array}$ & c. $1225 \mathrm{C}>\mathrm{T} / \mathrm{p} .(\mathrm{Gln} 409 \mathrm{Ter})$ & Loss \\
\hline 4 & 5 & $\mathrm{D} / \mathrm{N}$ & $\begin{array}{l}\text { SHH-activated, } \\
\text { TP53-WT }\end{array}$ & Lost & $\begin{array}{r}\text { c. } 2731 \mathrm{G}>\mathrm{T} / \mathrm{p} . \\
\quad(\mathrm{G} \ln 911 \mathrm{Ter})\end{array}$ & c.3030dup/p.(Asn1011GlnfsTer134) & Loss \\
\hline 5 & 5 & $\mathrm{D} / \mathrm{N}$ & $\begin{array}{l}\text { SHH-activated, } \\
\text { TP53-WT }\end{array}$ & Lost & c. $676 \mathrm{C}>\mathrm{T} / \mathrm{p} .(\operatorname{Arg} 226 \mathrm{Ter})$ & c.1197G > A/p.(Trp399Ter) & Loss \\
\hline 6 & 5 & $\mathrm{D} / \mathrm{N}$ & $\begin{array}{l}\text { SHH-activated, } \\
\text { TP53-WT }\end{array}$ & Lost & WT & c. $2308 \mathrm{C}>\mathrm{T} / \mathrm{p} .($ Arg770Ter) & Copy neutral-LOH \\
\hline 7 & 5 & $\mathrm{D} / \mathrm{N}$ & $\begin{array}{l}\text { SHH-activated, } \\
\text { TP53-WT }\end{array}$ & Lost & $\begin{array}{l}\text { c. } 1229 \mathrm{C}>\mathrm{T} / \\
\text { p.(Pro410Leu) }\end{array}$ & (p.Leu1086Ter) & Loss \\
\hline 8 & 6 & $\mathrm{D} / \mathrm{N}$ & $\begin{array}{l}\text { SHH-activated, } \\
\text { TP53-WT }\end{array}$ & Lost & $\begin{array}{l}\text { c.3578delC / } \\
\text { p.(Ser1193TyrfsTer30) }\end{array}$ & Somatic deletion & Loss \\
\hline 9 & 7 & $\mathrm{D} / \mathrm{N}$ & $\begin{array}{l}\text { SHH-activated, } \\
\text { TP53-WT }\end{array}$ & Lost & $\begin{array}{l}\text { c. } 741-1 \mathrm{G}>\mathrm{T} / \\
\text { p.(Glu1247Ter) }\end{array}$ & WT & Loss \\
\hline 10 & 8 & $\mathrm{D} / \mathrm{N}$ & $\begin{array}{l}\text { SHH-activated, } \\
\text { TP53-WT }\end{array}$ & Lost & $\begin{array}{l}\text { c. } 1000 \mathrm{C}>\mathrm{T} / \\
\text { p.(Gln334Ter })\end{array}$ & WT & Loss \\
\hline 11 & 8 & NOS (biopsy) & $\begin{array}{l}\text { SHH-activated, } \\
\text { TP53-WT }\end{array}$ & Lost & c.2499dup p.(Lys834Ter) & c.898del/p.(Ala300ProfsTer24) & Loss \\
\hline 12 & 9 & $\mathrm{D} / \mathrm{N}$ & $\begin{array}{l}\text { SHH-activated, } \\
\text { TP53-WT }\end{array}$ & Lost & $\begin{array}{l}\text { c. } 961 \mathrm{~A}>\mathrm{T} / \\
\text { p.(His681ArgfsTer58) }\end{array}$ & WT & Loss \\
\hline
\end{tabular}

$D / N$ Desmoplastic/nodular, $E N$ extensive nodularity, $I H C$ immunohistochemistry, $W T$ wildtype, $Y O$ year-old

an ELP1 mutation, confirming that this is a rare event, as already suggested by the previous literature [4].

To conclude, we demonstrated that ELP1 IHC is a highly specific and sensitive biomarker for identifying ELPI-associated MB and should be part of the neuropathologist's routine panel of antibodies to possibly screen a related predisposition syndrome in these children.

Supplementary Information The online version contains supplementary material available at https://doi.org/10.1007/s00401-022-02409-4.

\section{Funding No funding.}

Data availability Proteomic datasets were deposited to the Proteomics Identifications Database (PRIDE) with accession number PXD016832.

\section{Declarations}

Conflict of interest The authors declare that they have no conflict of interest directly related to the topic of this article.

Open Access This article is licensed under a Creative Commons Attribution 4.0 International License, which permits use, sharing, adaptation, distribution and reproduction in any medium or format, as long as you give appropriate credit to the original author(s) and the source, provide a link to the Creative Commons licence, and indicate if changes were made. The images or other third party material in this article are included in the article's Creative Commons licence, unless indicated otherwise in a credit line to the material. If material is not included in the article's Creative Commons licence and your intended use is not permitted by statutory regulation or exceeds the permitted use, you will need to obtain permission directly from the copyright holder. To view a copy of this licence, visit http://creativecommons.org/licenses/by/4.0/.

\section{References}

1. Creppe C, Malinouskaya L, Volvert M-L et al (2009) Elongator controls the migration and differentiation of cortical neurons through acetylation of alpha-tubulin. Cell 136:551-564. https:// doi.org/10.1016/j.cell.2008.11.043

2. Setiaputra DT, Cheng DT, Lu S et al (2017) Molecular architecture of the yeast Elongator complex reveals an unexpected asymmetric subunit arrangement. EMBO Rep 18:280-291. https://doi. org/10.15252/embr.201642548

3. Waszak SM, Northcott PA, Buchhalter I et al (2018) Spectrum and prevalence of genetic predisposition in medulloblastoma: a retrospective genetic study and prospective validation in a clinical trial cohort. Lancet Oncol 19:785-798. https://doi.org/10.1016/ S1470-2045(18)30242-0

4. Waszak SM, Robinson GW, Gudenas BL et al (2020) Germline Elongator mutations in Sonic Hedgehog medulloblastoma. Nature 580:396-401. https://doi.org/10.1038/s41586-020-2164-5

Publisher's Note Springer Nature remains neutral with regard to jurisdictional claims in published maps and institutional affiliations. 